\title{
Olhares, práticas e evidências
}

António Faria-Vaz*

«Breastfeeding decreases health care costs by reducing the incidence and severity of illness among infants and young children, while mothers' health is also protected. Employers need to know that supporting their women workers' desire to breastfeed their babies is also good business because it reduces employee absenteeism"

Gro Harlem Brundtland Directora Geral da OMS

$\mathrm{N}$ o presente número da revista, através do Dossier, abordamos o tema do aleitamento materno.

A amplitude dos benefícios a curto, médio e longo prazo associados ao aleitamento materno é de uma dimensão tal, que a adesão a essas estratégias de promoção indica uma prática responsável por parte dos profissionais. Porventura, não existirá no domínio da Saúde Pública outra intervenção em que a relação custo-efectividade seja tão elevada, com excepção das relativas ao saneamento básico, e que tenha um impacto tão significativo em termos de ganhos em saúde.

Foi a partir da II ${ }^{a}$ Guerra Mundial que as taxas de aleitamento materno iniciaram o seu declínio. Só por volta dos anos 70 do século passado e após vários estudos, as autoridades de saúde decidem adoptar estratégias activas para a promoção do aleitamento materno. Os factores que determinam, ainda hoje, a redução da taxa do aleitamento materno são multifacetados e incluem a influência das normas culturais e da sociedade, problemas clínicos, a organização dos serviços de saúde e a falta de preparação dos profissionais de saúde. ${ }^{1}$

Um estudo recentemente publicado no BMJ, refere que as intervenções para a promoção do aleitamento materno deveriam ser essencialmente dirigidas às primeiras duas semanas após o nascimento, altura em que a maioria das mulheres interrompe o aleitamento. Adriano Cattaneo num editorial desse número, diz-nos que a intervenção precoce na gestão adequada dos problemas ligados ao aleitamento na primeira ou segun-

*Director da Revista Portuguesa de Clínica Geral da semana depois do parto, no momento em que a incidência da amamentação é mais elevada, combinadas com estratégias interactivas de apoio social, têm uma maior adesão das puérperas para a sua manutenção. Termina, afirmando que os determinantes da iniciação, da exclusividade e da duração do aleitamento são múltiplos, pelo que a eficiência de intervenções isoladas dificilmente serão efectivas na vida real. As intervenções serão tanto mais efectivas quanto assentem nas necessidades específicas de cada país e de cada comunidade.

Assim, temos um primeiro artigo que nos relembra a anatomia e fisiologia da lactação, ${ }^{2}$ tão importante para quem aconselha; um segundo, sobre aleitamento materno e prevenção de infecções, ${ }^{3}$ no qual se realça o importante papel dos profissionais ao informar, orientar e apoiar as mães na sua tomada de decisão, para alimentar o seu filho; um terceiro em que se especificam os problemas clínicos mais comuns, ${ }^{4}$ um interessante artigo que se debruça sobre os riscos da alimentação com leite artificial $^{5}$ e por último um outro artigo que nos dá a conhecer uma escala para avaliar a confiança das mães durante a amamentação, tão necessária aos profissionais no despiste das mães em risco de um precoce abandono da amamentação. ${ }^{6}$

Com este dossier pretendemos contribuir para a reflexão sobre esta temática, de modo a melhorarmos as taxas de aleitamento materno, preconizadas pelo Plano Nacional de Saúde, ao recomendar o incentivo desta prática, baseado nas orientações da OMS/UNICEF. Para a persecução deste importante objectivo de Saúde Pública os médicos de família são o elo imprescindível à sua concretização com sucesso.

\section{REFERÊNCIAS BIBLIOGRÁFICAS}

1. National Institute for Health and Clinical Excellence. Promotion of breastfeeding initiation and duration. Evidence into practice briefing. 2006. Acedido em 2009.07.12

2. Cattaneo A. Promoting breast feeding in the community. BMJ 2009;338

3. Órfão A, Gouveia C. Apontamentos de anatomia e fisiologia da lactação. Rev Port Clin Geral 2009 Mai-Jun; 25: 347-54

5. Cunha MA.Aleitamento Materno e Prevenção das Infecçôes Rev Port Clin Geral 2009 Mai-Jun; 25: 356-62 
5. Gouveia C, Órfão A. Problemas comuns da amamentação. Rev Port Clin Geral 2009 Mai-Jun; 25: 370-5

6. Pina M, Volpato C. Problemas comuns da amamentação. Rev Port Clin Geral 2009 Mai-Jun; 25: 370-5

7. Santos $\vee$, Sónia B. Contributo para a adaptação transcultural e validação da "Breastfeeding Sel-Efficacy Scale - Short Form"- versão portuguesa. Rev Port Clin Geral 2009 Mai-Jun; 25: 363-9

\section{ROSA MARIA GOMES}

Rosa Maria Gomes, nascida a 19-03-1957, natural de Moçambique, desde sempre gostou de desenho e pintura, mas é auto-didata. É Médica de Família e ocupa os seus escassos tempos livres a rabiscar.

De seu nome próprio Rosa Maria de São José decide tomar para nome artístico S. José.

1999

- Frequenta o Atelier de Pintura de Mestre Hélder Bandarra em Gaia desde Setembro de 1999 onde exercita a técnica de óleo sobre tela.

- Fez a primeira exposição individual em Outubro na Casa da Cultura da Freguesia de Paranhos «Origens».

- Participou pela primeira vez no «130 Encontro com a Arte», e voltou a participar nos anos subsequentes no $14^{\circ}$ e $15^{\circ}$, organizado pela Junta de Freguesia de Moreira da Maia.

- Em Dezembro, fez uma exposição individual na Junta de Freguesia da Senhora da Hora.

- Em Julho, participou numa exposição colectiva «A Arte e Imagem» das alunas do Mestre Hélder Bandarra no Fórum Jovem da Maia.

- Participou na III Bienal de Artes Plásticas do Rotary Clube da Maia - Fórum da Maia.

\section{1}

- Em Dezembro, nova exposição individual na Casa da Cultura da Freguesia de Paranhos «Virar da página». 2002

- Participou na IV Bienal de Artes Plásticas do Rotary Clube da Maia - Fórum da Maia.

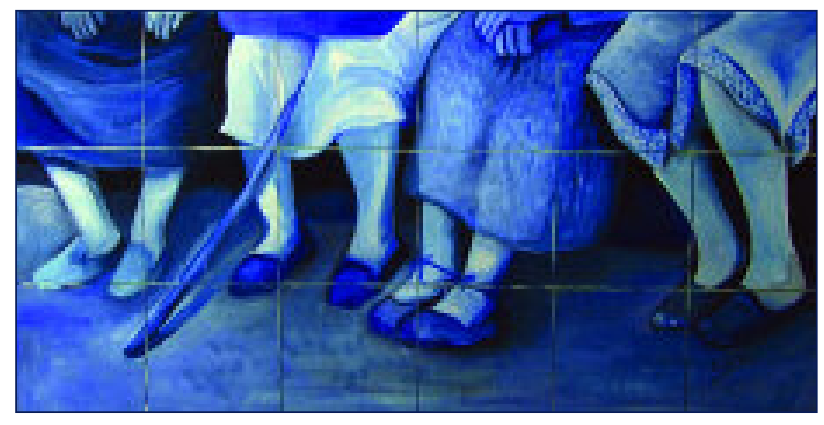

Esperando

Rosa Maria Gomes

2003

- Exposição colectiva no Fórum Jovem na Maia.

- Exposição colectiva na galeria do café MacQueen na Maia.

2004

- Exposição colectiva na galeria do café Magestic no Porto.

2005

- Participou na V Bienal de Artes Plásticas do Rotary Clube da Maia - Fórum da Maia.

2006

- Maio - exposição individual na Casa da Cultura da Freguesia de Paranhos «As cores dos sons».

\section{7}

- Janeiro - exposição individual na Ordem doa Médicos «A fantasia das cores».

- Dezembro - exposição individual na Galeria Espaço T - «Cheiro das cores para mãos que sentem» (exposição dedicada a invisuais com técnicas mistas de textura e cheiros). 